\title{
DE LA BENEVOLENCIA A LA CIUDADANÍA COMPASIVA: LA RECUPERACIÓN DE CONCEPTOS CLAVES PARA EL CULTIVO DE LA DEMOCRACIA
}

\author{
FROM BENEVOLENCE TO COMPASSIONATE CITIZENSHIP: THE RECOVERY OF \\ KEY CONCEPTS FOR THE CULTIVATION OF DEMOCRACY
}

\author{
Iván Pinedo Cantillo* \\ Grupo de Investigación Estudios sobre el desarrollo socio-moral, Departamento de Psicología, Universidad \\ Nacional de Colombia, \\ Bogotá - Colombia.
}

Recibido diciembre de 2017/Received Dicember, 2017

Aceptado marzo de 2018/Accepted March, 2018

\begin{abstract}
RESUMEN
El sufrimiento que atraviesa nuestra existencia y la vulnerabilidad que nos es constitutiva reclaman la presencia de ciudadanos que desde su repertorio emocional puedan asumir un compromiso efectivo de lucha contra las condiciones de pobreza, injusticia y opresión que pesan sobre la vida de tantas personas obstaculizando seriamente las posibilidades de florecimiento humano. Esta reflexión se asocia con el declive que en las actuales sociedades democráticas experimentan ciertos aspectos claves para la vida en sociedad, como la preocupación por el otro y sus necesidades apremiantes, al igual que una especial sensibilidad por el cultivo del bien común, de tal forma que lo que se percibe es un individualismo excluyente que deshumaniza a quienes viven así y rompe los lazos que nos vinculan con nuestras comunidades y con la humanidad en general. Frente a lo anterior, la rehabilitación de ciertas nociones sentimentalistas que otorgan un lugar privilegiado a la benevolencia y compasión en la esfera personal y en la deliberación pública, permite generar nuevas discusiones sobre el papel de las emociones en la vida moral y política, de tal forma que se establecen otros derroteros de reflexión que motivan a los ciudadanos a pensar en las actitudes y compromisos que son necesarios para cerrar la brecha que causa la insolidaridad y la apatía frente al dolor ajeno. Este artículo que recorre ideas sobre la filosofía y los sentimientos morales siguiendo los planteamientos de Hutcheson, Shaftesbury y Nussbaum es una contribución al debate sobre los principios éticos e ideales de justicia social que esperan su consolidación en las actuales sociedades democráticas, abiertas y participativas.
\end{abstract}

Palabras Clave: Benevolencia, Compasión, Sentimentalistas, Ciudadanía, Nussbaum.

\begin{abstract}
The suffering that crosses our existence and the vulnerability that is constitutive to us demand the presence of citizens that from their emotional repertoire can assume an effective commitment to fight against the conditions of poverty, injustice and oppression that weigh on the lives of so many people seriously impeding the possibilities of human flourishing. This reflection is associated with the decline that in the current democratic societies experience certain key aspects for life in society, such as concern for the other and their pressing needs, as well as a special sensitivity for the cultivation of the common good, in such a way that what is perceived is an exclusive individualism that dehumanizes those who live like this and breaks the ties that link us with our communities and with humanity in general. Faced with the above, the rehabilitation of certain sentimental notions that give a privileged place to benevolence and compassion in the personal sphere and in public deliberation, allows generate new discussions about the role of emotions in the moral and political life, in such a way that other courses of reflection are
\end{abstract}

* Autor correspondiente / Correspondig author: iapinedoc@ unal.edu.co 
established that motivate citizens to think about the attitudes and commitments that are necessary to close the gap caused by the lack of solidarity and apathy against the pain of others. This article that covers ideas about philosophy and moral sentiments following the approaches of Hutcheson, Shaftesbury and Nussbaum is a contribution to the debate on the ethical principles and ideals of social justice that await their consolidation in the current democratic, open and participatory societies.

Key Words: Benevolence, Compassion, Sentimentalists, Citizenship, Nussbaum.

\section{Introducción}

Las condiciones económicas, políticas y sociales que vivimos en este momento histórico de la humanidad delatan una profunda crisis de sentido de la vida que tiene como una de sus expresiones más visibles la indiferencia frente al dolor ajeno. Nos hemos acostumbrado a ver las noticias locales y mundiales de miles de personas sometidas a la marginación, la enfermedad, el hambre, la pobreza o la migración forzada, con el desdén de quien comprende que en este mundo convulsionado eso es lo que se puede esperar de esta civilización globalizada que nosotros mismos hemos engendrado.

Es cierto que el sufrimiento ha sido considerado por muchas tradiciones religiosas y filosóficas como una condición inherente a nuestra naturaleza humana que tarde o temprano se hará visible en nuestra existencia individual o colectiva. Los sufrimientos del ser humano son múltiples y de diversa intensidad. Quizá los más conocidos y extremadamente difíciles de afrontar son los provenientes de la finitud y caducidad de nuestro cuerpo que dan cuenta de nuestra radical vulnerabilidad frente a situaciones que se escapan a nuestro control. Las enfermedades, antiguas y nuevas, hacen descender al hombre a un nivel supremamente bajo de su ser, de tal forma que las ilusiones más profundas y los proyectos de vida trazados se oscurecen de manera incomprensible. Esta situación, unida a la impotencia para controlar los síntomas del cuerpo, poco a poco conduce a cualquier individuo a los umbrales de la angustia y la desesperación. Pero también tenemos los sufrimientos de carácter psicológico y social. La humillación experimentada en el trabajo o la guerra, la discriminación por la injusticia social, las condiciones de miseria que llevan incluso al hambre física, el maltrato, la soledad extrema, el cautiverio, la pérdida de los seres queridos y las patologías mentales que pueden conducir a la locura o el aislamiento, son tan sólo una pequeña lista de lo que un ser humano puede experimentar en un corto o largo periodo de su vida. Los efectos, en últimas, son similares: una punzante agonía de dolor que limita y amenaza por todos lados nuestra existencia empírica.

Las anteriores ideas nos llevan a pensar que hay sufrimientos inmerecidos, inexplicables existencialmente y otros que son provocados por la acción humana directamente o a través de instituciones políticamente injustas que descuidan sus compromisos básicos por defender unas condiciones de vida digna para sus ciudadanos. El resultado es un sufrimiento global que atraviesa a la humanidad. Esta situación, lejos de ser una abstracción intelectual, consiste en un dolor que muchas veces hemos provocado y que se refleja en las instancias más elementales de la sociedad: en los barrios pobres y marginales que crecen en las grandes urbes, en las muertes por desnutrición, en los jóvenes sin posibilidad de educación y en las urgencias de los hospitales congestionadas por individuos enfermos que llegan en graves condiciones de salud porque no cuentan en sus comunidades con un digno acceso a los servicios médicos. Todas estas realidades hablan de una humanidad que sufre y que demanda modelos alternativos de convivencia y de sensibilidad moral que respondan a la esencial fragilidad que nos constituye.

Frente a lo anterior, mucha gente siente el malestar en lo que se vive, pero difícilmente se dan a la tarea de ensayar nuevas experiencias de vida que reconstruyan esos lazos sociales que se han perdido bajo el signo de la apatía. Por su parte, quienes sufren como víctimas de todo ese cúmulo de dolor que esta maraña social, política y económica produce, anhelan el advenimiento de otra figura histórica en donde virtudes cívicas como la benevolencia, el amor a la justicia, la compasión, la solidaridad y, en general, el compromiso con la suerte de los demás, se erijan como los valores 
fundamentales sobre los cuales se construya un nuevo modelo de humanidad.

No es que el momento actual sea el único que reclame la presencia de estos valores que se consideran centrales para la vida en sociedad, ya en otros tiempos se proclamó la necesidad de una reflexión moral que tuviera como núcleo la naturaleza bondadosa del ser humano capaz de compadecerse del dolor que frecuentemente acompaña nuestra existencia. La búsqueda de una fórmula de benevolencia y compasión que asegure la felicidad del género humano hace parte la tradición filosófica de los últimos siglos, pero en las condiciones actuales en donde vivimos bajo el dominio de muchos males sociales, vicios de conducta e instituciones políticas de la sociedad inoperantes frente al sufrimiento de los ciudadanos, conviene volver la mirada sobre el origen y desarrollo de ciertas visiones del hombre que pueden ser inspiradoras para generar nuevas comprensiones de lo humano y para dar un nuevo aliento a la discusión pública en torno al bien común.

Pensadoras de reconocida influencia en el mundo contemporáneo, como la filósofa Martha Nussbaum, abogan por la recuperación de estas nociones de benevolencia y compasión que deben convertirse en reflexiones morales normativas para las actuales democracias liberales, abiertas y participativas. Para esta autora vivir es inseparablemente convivir: recibir y dar vida. Por supuesto, es una postura en radical oposición a la lógica del lucro, la productividad y el carácter utilitario de cada ser humano, en donde el beneficio recae sobre el propio sujeto que desconoce con frecuencia las consecuencias negativas de su ambición. Por su parte, en la lógica de la cultura de la vida, en donde la compasión juega un papel privilegiado, la realización del individuo está en la plenitud de las relaciones con otras personas en donde es posible la comprensión de la vulnerabilidad que nos es constitutiva y la reciprocidad de dones.

Teniendo en cuenta lo anterior, en este artículo se ofrece inicialmente una reconstrucción filosófica de los orígenes de ciertas comprensiones laicas de la benevolencia y compasión, para luego analizar en el momento actual lo que se denomina una defensa de la ciudadanía compasiva como horizonte de reflexión moral que es pertinente para edificar una cultura de la democracia, los derechos humanos y la promoción de la vida digna. Para establecer un marco de discusión preciso dentro de esta reflexión, nos limitaremos a considerar los aportes de los sentimentalistas británicos del siglo XVIII a la construcción de una visión positiva del ser humano en donde la benevolencia ocupa un lugar relevante como fuente de relaciones sanas y solidarias entre individuos y grupos. Este análisis implicará una breve comprensión de la transición del concepto de compasión propio de la tradición judeo-cristiana a la visión de benevolencia planteada por la ética sentimentalista. Luego nos centraremos en los aportes de la teoría de las emociones de Martha Nussbaum y su ideal de ciudadanía compasiva como principio rector que debe orientar la cultura democrática en el siglo XXI.

Iniciamos, pues, este recorrido teórico asumiendo los conceptos de los sentimentalistas británicos modernos como reflexiones que, si bien se dieron en otro contexto histórico, siguen teniendo validez como nociones que permanecen en el trasfondo de muchos problemas actuales y que permean diferentes comprensiones de lo humano que merecen ser rehabilitadas en nuestro mundo cada vez más convulsionado.

\section{Sentimentalismo y benevolencia}

La voluntad o deseo de hacer el bien al otro, de querer lo bueno o beneficiar con nuestra acción a otras personas se denomina benevolencia. Hume en el Tratado de la naturaleza humana la definía como "un deseo de felicidad hacia otra persona y una aversión contra su desgracia". En el caso específico de la compasión el conocimiento del mal por el que atraviesa otro ser humano, y de las causas que lo originan, pone al compasivo a idear los medios para remediar tal situación o procurar su alivio. En la compasión la benevolencia asoma, por tanto, como una voluntad o deseo de eliminar el mal ajeno porque no se quiere la prolongación de su desventura, esto se traduce en que se procura el bien del otro y se contempla con la acción compasiva un bienestar futuro, así muchas veces no llegue a hacerse efectiva la eliminación total del sufrimiento físico, moral o social por el que se está atravesando: "Sabemos con toda seguridad que la compasión es una protección provisional frente al sufrimiento, pero es lo único que tenemos, es el precio a pagar por nuestra finitud" (Mélich, 2010, p. 219). Esta visión de la compasión en estrecha relación con la benevolencia hunde sus raíces en la modernidad, por eso conviene comprender la 
evolución de estos dos conceptos que pueden ser iluminadores para las actuales condiciones sociales, políticas y económicas en que nos encontramos. Los sentimentalistas británicos del siglo XVIII: Shaftesbury y Hutcheson, comprendieron bastante bien la situación de indigencia y fragilidad que conforma la naturaleza humana, también la realidad del egoísmo y la búsqueda de intereses particulares que afectan sin cesar a los hombres y mujeres de cualquier condición social. Por eso, preocupados por estas singularidades humanas, dirigieron su reflexión a buscar una fundamentación del conocimiento moral, no en la razón fría de Kant que hace que el ser humano se plantee de manera consciente aquellas normas que valdrían para todo tiempo y lugar, independientemente de sus intereses, sus simpatías o los vínculos afectivos con la situación o personas involucradas, sino en el denominado sentimiento moral que es capaz de unir en el corazón los dictados de la sabia razón con las contingencias inevitables de la vida (Mauri, 2005).

La llamada ética sentimentalista de la ilustración escocesa ayuda a dilucidar bastante bien cómo aparece la idea de benevolencia y compasión que transformó la tradicional piedad cristiana, cimentada en el fervor y deberes religiosos del creyente, hacia una visión filosófica del hombre más fraterna y cargada de reciprocidad. En el ambiente social y político del siglo XVIII la vieja visión religiosa de la caridad, que se traducía en obras de misericordia, tanto corporales como espirituales, y de beneficencia para el pobre y desamparado, fue asumida por los burgueses en una dirección más laica y desligada de las jerarquías eclesiásticas. Se trata de un esfuerzo por pensar la realidad social sin referencias religiosas ofreciendo una perspectiva esperanzadora que se fundamenta en una idea más positiva de la naturaleza humana. Para tal efecto, los autores de esta corriente de pensamiento se enfrentan al problema de dilucidar hasta qué punto la realidad humana puede dar pie a una organización moral y social que debe construirse sobre la base de la desconfianza y el egoísmo, como planteaba Hobbes, o por el contrario puede permitirse una fundamentación distinta confiada en la capacidad de cooperación y en la voluntad humana de hacer el bien (Oviedo, 2016).

En este contexto, la caridad, que hasta entonces había sido un gesto que daba satisfacción individual y hablaba de la magnanimidad de quien era caritativo, se transforma en benevolencia, en un sentimiento que es motivo de solidaridad, que es parte de una empatía hacia los demás seres humanos que nos hace dolernos por sus desgracias y ponernos imaginariamente en su lugar, lo que constituye la base de la compasión como emoción moral dirigida al sufrimiento ajeno.

La tradición cristiana de la compasión, que fue la comúnmente aceptada hasta la modernidad, entendía este sentimiento como una faceta del amor de Dios manifestada para con el afligido, el infeliz y el pecador. Para el cristianismo cada ser humano se ubica al menos en una de estas categorías. En este sentido, la compasión del Padre Eterno se preocupa por restablecer nuestra plena dignidad humana, la cual tiene su origen en el conocimiento de que somos dignos de ser amados, incluso de ser amados por Dios a pesar de nuestras debilidades. El cristianismo defiende en sus raíces una historia de salvación para el hombre sustentada en la misericordia de Dios que se preocupa por el sufrimiento humano: "He visto la opresión de mi pueblo en Egipto, he oído sus quejas contra los opresores, me he fijado en sus sufrimientos y he bajado a liberarlos" (Éxodo 3,7-8). El Antiguo Testamento constantemente relata la intervención de Dios en favor de su pueblo sufriente, lo cual constituye una novedad desde el punto de vista religioso, pues el Padre Creador aparece como un ser misericordioso que comprende la condición humana, sale al encuentro del hombre y busca la liberación de aquello que le oprime y le causa dolor. El texto del Eclesiástico 2, 11 confirma una vez más esta comprensión de Dios: "El señor es compasivo y misericordioso, perdona los pecados y salva en la hora de la tribulación".

En el Nuevo Testamento, en la Segunda Epístola a los Corintios (II Cor. 1, 3-7), Dios es descrito como "el Padre de la compasión" afirmando que el consuelo que él nos produce nos permitirá consolar a otros. En esta misma línea de reflexión, la "Buena Nueva" que Cristo viene a comunicarnos es, ante todo, que Dios nos ama. Pero no se trata de una noción filosófica, sino que Jesús manifiesta el amor divino en su propia vida personal. Cristo anuncia este amor y lo prueba con su vida, su muerte y resurrección. En Cristo el amor divino se hace un sentimiento vivo, poderoso, cuya manifestación visible es la compasión, particularmente para con los pobres, enfermos y marginados (Sobrino, 1993). 
Jesús personifica la auténtica esencia de la compasión y basado en lo que teológicamente se denomina el principio de misericordia pide a sus seguidores actuar compasivamente hacia los demás, preferentemente hacia aquellos que se encuentran en situación de necesidad y exclusión social. La misericordia es, pues, una actitud fundamental ante el sufrimiento ajeno, en virtud de la cual se reacciona para erradicarlo por la única razón de que tal sufrimiento oprime al hombre y limita el desarrollo de todas las potencialidades humanas que son necesarias para vivir con dignidad. En este contexto, la actitud del buen Samaritano que narra el Evangelio de San Lucas 10, 29-37 se convierte en el comportamiento altruista por excelencia que se desprende del mensaje y obra de Jesús de Nazaret (Sobrino, 1992).

Así, pues, como derivación del amor de Dios, la persona que recibe la compasión divina es invitada a ser portador de ella, a participar de ella perdonando a quienes les ofenden, abriéndose a las necesidades de otras personas y ocupándose de la pobreza material o espiritual concreta de aquellos que el Señor coloca en su camino. Esta actitud hacia el prójimo será predicada por el cristianismo primitivo bajo la idea de caridad o amor fraterno que instaura una comunión de vida con los demás sin tener en cuenta su condición social, su cultura o nación.

Frente a lo anterior, la pregunta de la filosofía moral moderna consistirá en cómo fundamentar la compasión sin recurrir a categorías teológicas que le den sentido a esta virtud que se percibe como un pilar básico para la vida en sociedad. Es claro que en los textos bíblicos encontramos relatos alusivos a la compasión, pero desde la filosofía es necesario desarrollar otro tipo de argumentaciones que le den sustento a esta conducta de ayuda que es importante para afrontar diversos problemas y necesidades humanas.

Esta búsqueda filosófica se concretizó en buena medida en las nuevas orientaciones sobre el conocimiento moral que surgieron en la modernidad y que representaron un cambio de carácter revolucionario al introducir distintas nociones de fraternidad y de preocupación por los demás sustentadas en una visión del hombre que no dependía estrictamente de mandatos religiosos para obrar correctamente, más bien se fundamentaban en una reflexión ética secular en donde la percepción de la fragilidad del otro, y el deseo de su bienestar, eran motivos suficientes que impulsaban a acabar con los padecimientos humanos recurriendo a toda la ayuda disponible (Dixon, 2008). En este sentido, el sentimentalismo moderno, al incorporar factores emocionales en el conocimiento moral, obra una modificación fundamental en la visión que teníamos de humanidad: de vernos abstractamente como un grupo de hermanos hijos de un mismo Padre que está en los cielos pasamos a vernos como compañeros de camino sometidos a los mismos avatares de la fortuna y el sufrimiento, por tanto seres responsables los unos de los otros, pues sólo otro ser humano puede comprender nuestra condición en este mundo y puede hacerse cargo de ella, independientemente si comparte o no la misma creencia religiosa (Fiering, 1981). Naturalmente el principio del amor al prójimo sigue manteniéndose en el trasfondo de estas ideas, pero la reflexión moral deja de gravitar en torno a concepciones metafísicas acerca de un orden divino que rige todo lo contingente para cimentarse en aspectos emocionales que debían ser justificados.

Lo anterior significó en la reflexión filosófica la aparición de diferentes discursos y formulaciones conceptuales que reivindicaban el amor a la humanidad y un intento por exaltar la naturaleza buena del ser humano que propende por la justicia en lugar de la tesis del hombre gobernado por el interés egoísta ${ }^{1}$, o la naturaleza corrompida y caída del ser humano proclamada por la teología calvinista de los siglos XVII y XVIII ${ }^{2}$.

Salguero (2011), remitiéndose a la genealogía moderna de la benevolencia, nos recuerda que fundamentalmente es una virtud ilustrada que trajo nuevas perspectivas para la vida en sociedad, tales como: un deber que promueve el bien común incluso cuando no se espere una retribución inmediata; un entusiasmo natural por el bien público a modo de pacto natural originario; una constante inclinación a mantener una acción generosa humanitaria universal y una instancia desiderativa que, desde una antropología optimista, rechaza el egoísmo como estructura última del ser humano y tiende de manera constante a la concordia con todos los agentes racionales. Esto se puede analizar con mayor detenimiento en las tesis defendidas por algunos de los más insignes representantes del sentimentalismo moral como son Shaftesbury y Hutcheson.

El planteamiento ético de Lord Shaftesbury descansa en una concepción de la naturaleza 
humana según la cual el ser humano tiende de modo natural hacia el bien y a aborrecer el mal. Esta atracción hacia el bien constituye lo que denomina el sentido moral: se trata de una verdadera antipatía o aversión hacia la injusticia y hacia lo malo, y una verdadera inclinación o amor hacia la equidad y hacia lo bueno a causas de su propia belleza natural y valor. La naturaleza equipa por tanto al hombre con una facultad que le permite descubrir el mundo moral. El sentido moral le dice a cada individuo qué actos son buenos y virtuosos, porque gracias a ese sentido las personas sienten instintivamente que algunos actos son correctos y que otros no lo son (Mauri, 2005).

Para explicar cómo opera este sentido moral, Shaftesbury recurre al mundo de la experiencia para hacer un tipo de comparación analizando cómo obran los sentidos. Cuando hay un objeto externo con sus cualidades primarias y secundarias somos impresionados en nuestros sentidos, tenemos una determinada percepción del objeto. Esa captación de cualidades nos lleva a considerar ese objeto como armonioso, proporcional, deforme o bello. De forma similar cuando estamos en presencia de una acción, de una conducta o frente al carácter de un individuo recibimos una serie de imágenes que nos impactan, entonces "el corazón siente, valora, no permanece neutral, toma partido aprobando lo que es honesto y reprobando lo que no le parece tal" (Mauri, 2005, p. 19).

El análisis de las acciones es una actividad del entendimiento, pero es el sentido moral el que califica, el que da una valoración moral. Tras el análisis racional de una conducta o de una acción aparece la valoración moral. En virtud del sentido moral somos capaces de apreciar que algo es bueno diferenciándolo de lo malo. Mauri, quien ha desarrollado más ampliamente estas ideas nos dice:

El sentido moral no es diferente de cualquiera de los demás sentidos. Como ellos, afirma Shaftesbury, es capaz de captar lo que la realidad ofrece, que, en el caso del sentido moral, es la dimensión buena o mala de los actos o caracteres morales. En virtud del sentido moral podemos diferenciar lo correcto de lo incorrecto, y tener sentimientos consecuentes con lo discernido. Estos sentimientos, que nacen espontáneamente en el hombre, le mueven a aprobar o reprobar motivos, actos o caracteres. (Mauri, 2005, p. 66).
Para este filósofo ilustrado, por tanto, el sentimiento moral es asumido como una facultad de la naturaleza humana que le permite al hombre descubrir el mundo moral. En definitiva su esencia consiste en captar la dimensión buena o mala de los actos o caracteres morales. Este sentimiento es por consiguiente la prueba de la realidad de la virtud.

Ahora bien, el sentido moral es también para Shaftesbury una disposición moral y benevolente del hombre hacia los demás. El sentido moral está intrínsecamente vinculado a la benevolencia como tendencia natural que lleva al hombre a estar interesado por sus semejantes. La disposición de benevolencia es esencial a nuestra naturaleza y es el fundamento para la vida en sociedad. Se trata, por consiguiente, de una reflexión que sale al paso a la escuela del egoísmo que propone al amor propio como motor de las acciones humanas y origen de la sociedad. Según esto, no existen diferencias entre el interés público y el interés privado, puesto que por el primero se consigue el segundo, que es el que constituye la felicidad personal: el interés por los demás es la clave de la propia conveniencia, es el camino para alcanzar la felicidad individual (Shaftesbury, 1997).

En continuidad con lo anterior, para Shaftesbury el sentimiento moral es universal, se encuentra en todos los hombres, es común a toda la humanidad, de tal forma que es éste sentir el que otorga a las normas morales su carácter universal porque cada hombre, o la mayoría de los hombres, coinciden en la misma opinión o decisión moral acerca de una determinada acción. Con estas ideas el filósofo escoces trata de salir al paso a cualquier indicio de relativismo moral emotivista, no obstante su obra no es precisa en explicar qué sucede cuando alguien o algunos individuos presentan un sentir "incorrecto" frente a una determinada situación, es decir, el problema del origen del error en el conocimiento moral. Shaftesbury no profundiza mucho al respecto, pero deja algunas nociones estableciendo que este sentir incorrecto se debe a una falta de identificación con el otro y a una ausencia de reconocimiento del otro como un semejante, aspecto que implica una inadecuada relación con el mundo y con todo lo que lo compone; en otras palabras la sensibilidad de tal individuo no está conectada con la de otros seres humanos, de tal forma que sus afectos presentan algún tipo 
de desorden que le impide comprender el orden moral de los acontecimientos. Este es un aspecto no muy preciso en la filosofía de Shaftesbury, pero más allá de estas discusiones, su pensamiento es una clara reivindicación de la benevolencia y el amor a la humanidad que posibilita establecer una comunidad moral y política en donde se conjura el egoísmo y la violencia que se produce cuando la suerte del otro y sus necesidades resultan completamente ajenas para nuestros afectos.

Para Francis Hutcheson (1999), en el ser humano se destaca una capacidad para aprobar y censurar inclinaciones y actos, disposición que recibe el nombre de sentido moral y cuya existencia se cuenta entre las inclinaciones naturales. El sentido moral es una determinación o disposición de nuestras mentes de recibir las ideas simples de aprobación o condena, procedentes de los actos observados; disposición que es anterior a cualquier concepto del beneficio o daño que esas acciones puedan proporcionarnos. Ante las acciones humanas, el sentido moral automáticamente reacciona de dos modos: o se place -y con ello aprueba- o se duele -y de este modo desaprueba-. Por consiguiente, el sentido moral nos hace espectadores de los demás y nos hace sentir pena o placer como efecto de nuestra observación. Observamos las acciones como exteriores en relación con nosotros y nuestro sentido moral nos permite sentir de manera espontánea e instantánea aprobación o condena por ellas. Sin este sentido moral un hombre no aprobaría más que lo que fuese conveniente para sus fines particulares, aunque viese lo que es conveniente para promover el bien de los demás (Mauri, 2005).

En relación con los demás seres de la naturaleza Hutcheson considera que sólo los seres racionales podemos reflexionar sobre nuestras pasiones y juzgar si son buenas o malas. Los demás seres sensibles sólo sienten placer y pena inmediatos, sin poder representárselos o tener un sentimiento frente a estas pasiones. De esto se deduce que el sentido moral, aunque puramente sensible, es exclusivo de los seres racionales. Esto conduce a establecer una diferencia entre el bien natural y el bien moral: tan sólo el último es percibido como benevolencia y puede despertar el amor y la admiración del espectador. Esta exclusividad da lugar no sólo a una forma de identificación entre los seres racionales, sino también a la posibilidad de reconocer qué tienen en común, lo cual abre explícitamente el camino hacia la formación de una comunidad moral (Hurtado, 2013).

En su Investigación sobre el origen de nuestras ideas de belleza y virtud, Hutcheson (2004), considera que el sentido moral se complace en más alto grado o encuentra mayor contento ante la benevolencia entendida como la búsqueda del bien público o general, es decir, la determinación a complacerse con la felicidad de los otros y a no sentir placer por su situación de miseria o dolor; estos actos benevolentes, que surgen al margen de cualquier interés personal, y que están orientados al bien público, son precisamente aquellos que pueden ser calificados como "buenos". La benevolencia es, pues, una inclinación cuyo objeto es la felicidad de los demás, por esta razón experimentamos satisfacción en nuestro interior cuando sentimos esta tendencia con nuestro sentido moral, de ahí que sea el fundamento de la virtud y un motivo esencial para la actuación moral (Seoane, 2004). En contraste con lo anterior, el egoísmo aparece como una inclinación que busca la propia felicidad a costa de los demás, por tanto es un motivo para la desaprobación desde el sentido moral. Hutcheson asume, por tanto, que la moralidad está vinculada a un tipo de crecimiento humano que se da cuando las personas salen de sí mismas atendiendo a los intereses de los demás, dejando a un lado la búsqueda de ventajas personales para mirar positivamente por la felicidad de los demás. Con los sentimentalistas británicos se inaugura, por tanto, una comprensión de la naturaleza buena del ser humano que va a tener importantes repercusiones para la vida en sociedad. El hombre se reconoce como un ser capaz de hacerse cargo del sufrimiento de sus congéneres y comprende que la reciprocidad, la solidaridad y la generosidad son caminos apropiados para aliviar nuestra condición humana característicamente menesterosa. Igualmente la benevolencia se reconoce como el camino que conduce a un progreso en la sociedad al invitarnos a dejar de gravitar sobre nosotros mismos, para pensar en la felicidad de los demás, lo cual es la base de una vida pública sana y armoniosa (Seoane, 2001).

Como se ha anotado, en la filosofía moderna se planteó un nuevo horizonte de reflexión para las ideas de benevolencia y compasión tradicionalmente circunscritas al ámbito religioso. La benevolencia es vista por los sentimentalistas como una actitud natural de los propios individuos que no se justifica 
necesariamente apelando a abstracciones o entidades no humanas. Para los cristianos y miembros de otras confesiones religiosas, como el budismo, la bondad y la compasión seguirían siendo virtudes morales que se desprenden de una experiencia espiritual que motiva al interés por los demás, pero desde la filosofía las posturas sentimentalistas permitieron que la reflexión sobre estas actitudes humanas tomaran otros rumbos de investigación que devienen en las preguntas y debates en torno a la naturaleza del comportamiento altruista: ¿Es posible la conducta prosocial altruista?, ¿puede una persona ir más allá de los límites del beneficio propio y prestar ayuda motivada por el bienestar de los demás?, ¿son pautas de comportamiento hereditarias o aprendidas?, ¿hay diferencias entre los animales y los seres humanos? (Seglow, 2005). Estas preguntas sobre el altruismo, por su extensión y complejidad, son objeto de estudio en otro tipo de investigaciones, por ejemplo, el amplio análisis que Dixon (2008) ofrece sobre los orígenes y evolución de este concepto. En lo que aquí concierne basta con formular que el altruismo es un problema que se desprende de la pregunta por la naturaleza benevolente del ser humano. A continuación conviene reflexionar sobre el otro concepto que orienta el presente análisis.

\section{Compasión}

Con la compasión ha sucedido algo similar al concepto de benevolencia que se desligó en la modernidad de su tradicional justificación religiosa y ha vuelto a ser objeto de discusión desde una perspectiva netamente filosófica. En las últimas décadas, de la mano de un aristotelismo renovado que busca responder a muchas demandas morales del hombre actual que no encuentran plena satisfacción en los paradigmas deontológico y utilitarista que primaron en buena parte del siglo $\mathrm{XX}$, se viene desarrollando una recuperación de la ética de las virtudes que propende por la formación del carácter, el papel de las emociones en la vida moral y la potencialización de diversas actitudes que son necesarias para generar vínculos comunitarios fuertes y una preocupación auténtica por las necesidades de los demás ${ }^{3}$.

La compasión hace parte de este grupo de virtudes que guardan un estrecho vínculo con la naturaleza de las emociones del agente, sus motivaciones y deseos, de tal forma que es un concepto que hoy en día tiene enorme relevancia normativa tanto para la vida individual como para la deliberación pública.

En este contexto, y a más de dos siglos de distancia de los sentimentalistas británicos, Martha Nussbaum es una de las intelectuales más reconocidas en el momento actual que rehabilita, desde la filosofía y la psicología de las emociones, diversas nociones sobre la naturaleza de la compasión y su pertinencia para las actuales sociedades democráticas liberales, abiertas y participativas. La idea de compasión que expone Nussbaum no se identifica o equipara con el sentimiento de lástima que surgió en la tradición cristiana bajo el concepto de obras de misericordia de la Iglesia, lo cual implica una serie de prácticas orientadas a aliviar el sufrimiento ajeno: visitar a los enfermos, dar de beber al sediento, vestir al desnudo, y así toda una serie de acciones benevolentes que daban cuenta del compromiso del creyente con el mensaje evangélico (Vives, 1953). Si bien durante mucho tiempo la compasión ha tenido este ropaje cristiano, las ideas de Nussbaum nos dan a entender que este vestido tradicional no es la expresión definitiva y acabada de esta emoción, todavía es factible examinarla desde otras perspectivas de tal forma que hable al hombre actual e incluso motive a la acción moral.

La idea de Nussbaum tiene cimientos asentados en la filosofía y en la psicología, su orientación es más existencial y enraízada en la noción aristotélica de florecimiento humano que nos invita a una preocupación auténtica por proteger el conjunto de potencialidades fundamentales del ser humano que es necesario desarrollar para que un individuo alcance la plenitud de lo que implica ser persona. De hecho los detractores de la compasión, como Nietzsche, recurren frecuentemente a la imagen de la piedad cristiana, caracterizada en su sistema de pensamiento como el "sentimiento de los débiles", para criticar y poner bajo sospecha a esta emoción que precisamente Nussbaum quiere rehabilitar al indicarnos un camino para evitar en lo posible cualquier forma de sufrimiento, y para ampliar, educar y estabilizar el interés por los demás.

Inspirada en Aristóteles y en el estoicismo antiguo, Nussbaum concibe una teoría cognitivoevaluadora de las emociones que entiende a éstas como un tipo especial de juicios: juicios de valor o evaluaciones que permiten ver el mundo desde el punto de vista de nuestro esquema de objetivos 
y proyectos: las cosas a las que asignamos valor en el marco de una concepción de lo que para nosotros significa el florecimiento de una vida humana buena (Nussbaum, 2006; 2008; 2014). Si bien su teoría no aborda todo los tipos de emoción, en Paisajes del pensamiento: la inteligencia de las emociones expone una amplia interpretación de la dimensión cognitiva y evaluativa de la compasión, considerada positivamente por la reflexión filosófica como una emoción que ofrece un buen fundamento para las acciones adecuadas desde el punto de vista moral.

Para nuestra autora la compasión es un sentimiento que va asociado directamente con la justicia y ocupa un lugar central en sus propósitos educativos y en su ideal de construir una nueva cultura política pública. Con la compasión se garantiza que los sujetos se apropien de la fragilidad y sufrimiento de los otros lo que hace que sea una emoción moral fundamental o la emoción social básica (Nussbaum, 1996). Por tanto es una emoción que requiere un conjunto complejo de conceptos relacionados con los valores morales, una conciencia de las distinciones morales, de lo correcto o incorrecto, justo o injusto, y una capacidad adaptativa para interpretar correctamente el estado mental de alguien que puede influir en nuestro bienestar (Izard, 1977; Lewis, 1993; Neblett, 1981).

La compasión es una emoción que posee un potencial relevante para la reflexión ética porque va asociada a la deliberación humana de cómo vivir bien reconociendo la fragilidad, la reciprocidad y la indulgencia. Es una intuición moral que nos informa acerca del mejor modo de comportarse para contrarrestar mediante la consideración, el respeto y la benevolencia la extrema vulnerabilidad de las personas, de tal forma que puede ser vista como un mecanismo protector o compensador de esa fragilidad esencial que nos es constitutiva. También es una emoción vinculada con la búsqueda de la justicia social y la acción moral en donde se ponen en juego la conciencia por medio de juicios, decisiones y compromisos que dan cuenta de los principios y fines que orientan a la persona, y que son capaces de humanizar la realidad al traducirse en obras para los demás. Por esta razón la compasión en el pensamiento de Nussbaum $(1996 ; 2003 ; 2008)$ puede tener un rol importante dentro de una teoría ética normativa que tenga en cuenta las emociones como elementos centrales que ayudan a advertir sobre la presencia de daños morales y sufrimiento que obstaculizan el desarrollo de una vida humana buena.

Siguiendo las ideas aristotélicas, Nussbaum (2008) comprende la compasión como una emoción dolorosa ocasionada por la conciencia del infortunio o sufrimiento inmerecido de otra persona: "un cierto pesar por la aparición de un mal destructivo y penoso en quien no lo merece, que también cabría esperar que lo padeciera uno mismo o alguno de sus allegados" (Aristóteles, Retórica, 1385b13). En el trasfondo de esta emoción subyace la idea central que atraviesa la teoría de Nussbaum: no es una oleada irreflexiva de afectos, sino maneras de ver los objetos que se sustentan en creencias de diverso tipo.

Nussbaum reconoce los cimientos aristotélicos de esta emoción, pero llevará la argumentación filosófica a otros niveles de reflexión que rehabilitan el valor de la compasión para el hombre actual. Sus planteamientos, además de ser consistentes con las ideas antiguas, también se encuentran alineados con diversos estudios empíricos actuales que intentan explicar ciertos elementos claves que integran esta emoción: 1) reconocer el sufrimiento ajeno, 2) entender la universalidad del sufrimiento en la experiencia humana, 3) sentir por la persona que sufre y conectarse emocionalmente con su angustia, 4) tolerar cualquier sentimiento incómodo que pueda despertarse en una situación (por ejemplo, miedo, disgusto o enojo) para que permanezcamos abiertos y aceptemos a la persona que sufre, y 5) actuando o siendo motivados a actuar para aliviar el sufrimiento ( $\mathrm{Gu}$, Cavanagh, Baer, \& Strauss, 2017).

Según Nussbaum (2008), la compasión tiene una estructura cognitiva que permite esclarecer el valor ético de esta emoción tanto en la vida personal como en la deliberación pública. El primer juicio cognitivo que estructura la compasión es una creencia o una evaluación según la cual el sufrimiento de otro ser humano es grave, no trivial. Lo que la filósofa denomina el "juicio de gravedad" hace referencia a un tipo de pensamiento en donde se aprehende que hay ciertas circunstancias de la vida que no provocan una molestia superficial o pasajera, sino que obstaculizan la existencia completa de un individuo hasta generar un intenso dolor; son acontecimientos que afectan en profundidad el sentido de la vida del otro, sus posibilidades de realización, su dignidad como persona. 
El segundo requisito cognitivo que estructura la compasión es el "juicio de inmerecimiento" o creencia de que tal persona no debía ser víctima de un determinado sufrimiento. En este punto entra cierta noción de responsabilidad en las acciones, es decir, hay personas que de alguna manera buscan su dolor ya sea por riesgo, por negligencia o por obstinación en determinados comportamientos que se sabe de antemano son nocivos. Por ejemplo, el aficionado al casino que perdió en la ruleta un montón de dinero quizá no sea el más adecuado para ser objeto de nuestra compasión puesto que hay bastante responsabilidad en esa conducta que podía haber sido evitada por el individuo. Se trata de una percepción muy difundida en la mentalidad colectiva, pues no se tiende a compadecer con igual rapidez a quien le ha sobrevenido un mal por causa de sus acciones imprudentes, desobedientes o perniciosas, más aún cuando otros le habían advertido sobre las posibles consecuencias negativas de su conducta.

Esta reflexión sobre la compasión, tal y como la concibe Nussbaum, conlleva una noción sobre la reparación de la injusticia, la reciprocidad en las relaciones sociales y el restablecimiento de las relaciones justas según el mérito: el socorro que se ofrece de alguna manera contribuye a reponer la justicia en aquel que nos interpela desde su frágil contingencia.

La idea de no compadecerse con igual presteza por el mal de quien se lo ha buscado o ganado por su obstinación, rebeldía o apego al vicio ya estaba presente en el pensamiento de Aristóteles y sigue teniendo vigencia en la sociedad actual: "la compasión verdadera entraña la creencia en la bondad del individuo doliente al que se dirige; al menos, la confianza en su irresponsabilidad respecto del mal que le azota" (Arteta, 1996, p. 21). Aristóteles argumentó que el sufrimiento merecido o buscado debería conducir a la culpa $\mathrm{y}$ al reproche, mientras que el sufrimiento inmerecido debería provocar compasión. Las teorías contemporáneas del merecimiento (Feather, 2006) y la atribución de la culpa (Weiner, 1985) también hacen eco del análisis de Aristóteles y sugieren que las valoraciones de la culpa son importantes para el surgimiento de la compasión.

El sufrimiento inmerecido apela, por tanto, a nuestro sentido de la injusticia y se relaciona frecuentemente con aquellas personas que, en general, se consideran buenas pero por la vulnerabilidad que nos es constitutiva se ven enfrentadas a situaciones negativas que les acontecen:

Hay cosas realmente malas que les pueden suceder a las personas, sin mediar ningún fallo por su parte, o situándose más allá de su fallos. Al sentir compasión por otra persona, la persona compasiva acepta, entonces, cierta representación del mundo según la cual las cosas valiosas no siempre están a salvo y bajo control, sino que a veces pueden resultar dañadas por la acción de la fortuna.

(Nussbaum, 2008, p. 354).

Lo anterior es cierto, pero también podemos constatar en la experiencia que la compasión, como simple emoción, a veces brota como un impulso espontaneo frente a acontecimientos que ocurren con bastante premura, y no siempre es proclive a establecer las causas de un determinado sufrimiento, y en consecuencia las distinciones de merecimiento o inmerecimiento, inocencia o culpabilidad del sujeto, por tal motivo es importante establecer otros componentes cognitivos que ayuden a esclarecer el lugar de la compasión como testimonio en favor de la vulnerabilidad del hombre.

El tercer componente cognitivo es lo que Nussbaum denomina el juicio eudaimonista ligado al florecimiento de la persona. Este aspecto es de suma relevancia dentro del pensamiento de la filósofa norteamericana. Para Nussbaum, rehabilitando el pensamiento de Aristóteles, la compasión es la forma que tiene nuestra especie de ligar el bien de los otros a la estructura fundamentalmente eudaimonista, no egoísta, de nuestra imaginación y de nuestras preocupaciones más intensas: "para que se despierte la compasión se debe considerar el sufrimiento de otra persona como una parte significativa del propio esquema de objetivos y metas" (Nussbaum, 2008, p. 358). En este sentido se trata de un juicio en donde se toman las penurias de otra persona como algo que afecta el propio florecimiento, por tanto, es un componente necesario, indispensable para que se elicite la compasión.

En este contexto, Nussbaum reconoce que el juicio eudaimonista corresponde a un tipo de juicio de valor ligado al florecimiento de la persona y a la pregunta por cómo debemos vivir: "el objeto de la emoción es visto como importante para algún papel que desempeña en la propia vida de la persona" (Nussbaum, 2008, p. 53). Cuando 
investimos de valor o enorme importancia a una persona y su situación de sufrimiento entonces la interpretación de los acontecimientos cambia considerablemente porque nos desprendemos de cierta mirada neutra o indiferente frente al mundo. Nuestro objeto intencional de emoción se convierte en parte central de nuestra vida, de nuestro yo, es decir se encuentra en estrecha relación con nuestro florecimiento humano, con aquello que para nosotros resulta como una parte esencial de la vida buena. Por esta razón la filósofa nos dice:

Las emociones poseen un carácter local: adoptan un lugar peculiar dentro de mi propia vida (...). Incluso cuando se interesan por acontecimientos que tienen lugar a distancia o eventos del pasado, es porque la persona ha conseguido investir tales sucesos de cierta importancia dentro de su propio esquema de fines y objetivos. (Nussbaum, 2008, p. 53).

La ausencia del juicio eudaimonista explica en la teoría de Nussbaum por qué puede suceder que un individuo sienta en determinadas circunstancias la gravedad de la situación de una persona e incluso piense que es inmerecida, pero al no considerar al otro como un elemento valioso dentro de su esquema de objetivos y planes, y al no ver a la otra persona como un fin en sí mismo cuyo bien debe ser promovido, es plausible que no emerja la compasión: si no valoro a la otra persona como parte de mi propio círculo de interés es probable que no sienta ningún motivo para compadecerme. En este sentido, el juicio eudaimonista no requiere que quien siente compasión mantenga necesariamente una relación afectuosa con quien padece el sufrimiento, por ejemplo que tenga un vínculo singular de amor o parentesco, basta con el reconocimiento de que se trata de otra persona con la que se comparte la condición de vulnerabilidad la cual puede ser atraída hacia el ámbito de preocupaciones propias.

Lo anterior nos indica cómo el florecimiento humano es una idea ética que implica una noción sobre cómo ha de vivir el ser humano y de lo que es bueno para nosotros:

El florecimiento refiere a una vida humana plena, y la vida humana plena es aquella en la que no faltan aquellas cosas a las que atribuimos un valor. Los seres humanos no buscamos únicamente sobrevivir, sino que queremos hacerlo con cierta calidad. (Gil, 2016, p. 203).

Para subsanar estos posibles obstáculos que pueden aparecer en el reconocimiento del sufrimiento ajeno y en la integración de los acontecimientos a la noción de lo que para el agente posee valor o importancia de carácter personal, Nussbaum recurre a un cuarto componente cognitivo de la compasión que entra en ayuda del juicio eudaimonista, lo que denomina el "juicio de posibilidades parecidas". Se trata de la creencia según la cual las posibilidades de la persona que experimenta la emoción son parecidas a las del que padece el sufrimiento. Es, pues, un constructo que trata de salir al paso a la situación en donde otros (particularmente personas distantes o ajenas a mi entorno) no son considerados como fines en sí mismos, es decir, partes importantes del propio esquema de objetivos y proyectos (Nussbaum, 2008).

Este punto tiene relación con la idea de lograr empatía, así sea imaginaria, con la situación del otro, "ponerse en sus zapatos" y pensar que ese otro podría ser yo en forma real o hipotética atravesando tal adversidad porque soy un ser humano igual de vulnerable y expuesto continuamente a los avatares de la fortuna.

Es en este contexto en donde Nussbaum da cabida a la empatía (o imaginación comprensiva, como suele llamarla en algunas reflexiones) como un tipo de reconocimiento o comunidad entre yo mismo y ese otro que está sufriendo. El reconocimiento de otros como personas semejantes a uno mismo permite la extensión de este interés a las necesidades y deseos de las personas en general o a los de algún individuo particular cuya situación deja de ser indiferente. La imaginación empática acerca de las posibilidades y los obstáculos que están presentes en la vida de otra persona acorta la distancia que muchas veces establecemos con los demás, con su vulnerabilidad, con su dignidad como persona. Sin ese reconocimiento es probable que permanezcamos en la indiferencia al no valorar a la otra persona como parte del propio ámbito de preocupaciones y, por lo mismo, se opaca la extensión del interés por los demás. 


\section{Ciudadanía compasiva: las emociones en la deliberación pública}

El estudio de las emociones ocupa un lugar central dentro del pensamiento filosófico de Nussbaum, pero su interés por comprender la naturaleza de las emociones se encuentra fuertemente ligado a su preocupación por generar diversos principios éticos normativos que orienten a las actuales sociedades democráticas, liberales, abiertas y participativas a defender un modelo de humanidad y de ciudadanía en donde la consideración de aspectos relacionados con la justicia social y la igualdad de oportunidades para todos, el respeto a la dignidad humana y la comprensión de la vulnerabilidad que nos es constitutiva, se establezcan como ideas rectoras de la deliberación moral y política.

Según lo anterior, la visión de Nussbaum sobre la compasión como virtud moral individual tiene repercusiones en la vida pública de los ciudadanos. Se trata de una original reflexión que cambia la manera de ver esta emoción tradicionalmente considerada como una virtud que se ejerce en el ámbito de la vida privada, pero rara vez ha sido tratado como emoción política que toca aspectos fundamentales de la justicia social. Este es pues uno de los aspectos más llamativos de la teoría de Nussbaum.

El juicio evaluativo en torno a la situación de sufrimiento inmerecido de otra persona es un asunto que supera las fronteras del yo, y expande su influencia a las instituciones públicas y a las comprensiones de ciudadanía en general. En este sentido, la compasión debe mover a los ciudadanos a movilizarse en pro de la humanidad sufriente, llámesele hoy en día refugiados, víctimas de la guerra, mujeres oprimidas, migrantes, minorías o cualquier otro grupo vulnerable que no tenga por sí mismo otras posibilidades para su crecimiento humano. Entendida así, la compasión es una motivación para el desarrollo de la conciencia moral y la acción virtuosa que busca el bien no solo a nivel personal sino público. Este es un asunto que nos vincula con la visión del liberalismo político de fuerte raigambre rawlsiano que hace parte del pensamiento de Nussbaum, y que lleva a esta autora a extender su reflexión sobre la compasión hasta tocar problemas característicos de la justicia social y la necesidad de globalizar condiciones de vida digna para todos los seres humanos (Lariguet, 2015).
La situación, por ejemplo, de muchos niños desnutridos y sin educación es para Nussbaum un problema que debe preocupar a los demás seres humanos, puesto que allí está en juego el florecimiento de estas personas. Con hambre y sin educación las posibilidades de desarrollar todas las potencialidades humanas a nivel intelectual, biológico, social, comunicativo o estético se ven seriamente amenazadas. No es una cuestión sólo de percepción sino un hecho real y verificable que los niños, en esas condiciones, nunca podrán tener oportunidades de desarrollo como lo tienen aquellos que gozan de confort o tienen acceso a todos los bienes de la civilización (Pinedo \& Yáñez, 2017).

La indiferencia y la "invisibilidad" de este tipo de personas sufrientes es lo más ajeno al paradigma de la compasión. Para Nussbaum la compasión es un tipo de lealtad a la humanidad en donde se reconoce que otros son frágiles y que necesitan de nuestra asistencia más allá de su clase, género, raza o religión. De esta comprensión de nuestra radical vulnerabilidad y de la idea que todos tenemos la misma dignidad, independientemente del lugar que ocupemos en la sociedad, del partido político al que pertenezcamos, de nuestro grado de inteligencia o de los estudios que tengamos, surge la acción benevolente. La dignidad nos hace iguales, y este reconocimiento es base para construir una ciudadanía compasiva. Pero el asunto importante aquí es que la gente lo sienta así, es decir, que vincule sus emociones a esta consideración moral, y no sólo realice un ejercicio racional de comprensión de estas realidades humanas.

Nussbaum, se considera a sí misma como una pensadora que ejerce la filosofía en el sentido antiguo helenístico de "medicina para el hombre y sus problemas", por tal motivo quiere vincular su reflexión sobre la compasión y la benevolencia a su idea de justicia política expresada en su reconocido "enfoque de las capacidades": los umbrales mínimos de dignidad humana que deben ser considerados en una concepción razonable de justicia social (Nussbaum, 2012). La compasión se puede ejercer en cualquier momento y motivada por diversas circunstancias, pero si preguntamos a nivel de justicia política ¿cuáles son aquellos aspectos centrales que una noción de ciudadanía compasiva debe defender en las actuales sociedades democráticas, abiertas, liberales y plurales? La respuesta de la filósofa nos dirige a su idea de diez capacidades 
humanas fundamentales que conforman el marco normativo que toda sociedad justa y decente debe promover. Las capacidades, como bien lo afirma la autora son los derechos sociales mínimos que marcan el límite entre condiciones de vida digna para todos y niveles de vida infrahumana ${ }^{4}$.

En este punto podemos comprender la teoría de la compasión de Nussbaum como una bisagra que une la esfera moral individual (agencia del individuo) con la esfera de justicia que es propia de lo político y lo legal. De esta unión entre compasión y deseo de justicia política surge lo que Nussbaum denomina la noción de ciudadanía compasiva que se desprende de su teoría cognitivo-evaluadora de las emociones.

Ciudadanía en este contexto implica una actitud de vida proactiva que busca mejorar las condiciones de vida propias y de la colectividad. Esta postura significa algo más que votar, encierra también el desarrollo de la conciencia de que un ciudadano es un ser que hace parte de un todo y de que el beneficio al colectivo siempre repercute en el individuo, que tiene el compromiso de contribuir a la mejoría de la sociedad. Ciudadanía compasiva significa concretamente hombres y mujeres que son movidos por su repertorio emocional a la preocupación por los demás seres humanos, especialmente hacia aquellos a los que por razones de injusticia social son más vulnerables y con mayor propensión a no poder florecer humanamente teniendo en cuenta sus condiciones deplorables de vida: "uno de los peores aspectos de la privación es que despoja a la gente de sus aspiraciones y del sentido de la dignidad" (Nussbaum, 1997, p. 81). La compasión, por consiguiente, como virtud característica de la nueva ciudadanía puede estar acompañada de otras emociones pertinentes como la indignación por el maltrato a los débiles y la desaprobación de situaciones de exclusión, desigualdad o negligencia por parte de las instituciones públicas que deberían hacerse cargo de aquellas circunstancias en donde se percibe el hundimiento de personas en lo infrahumano.

La inclusión de las personas con discapacidad física y mental en las políticas públicas, por ejemplo, ocupa un lugar importante dentro de esta comprensión de la benevolencia que, más allá de la caridad, propone nuevas lecturas de la justicia social para corregir las deficiencias de un contractualismo clásico regido por principios netamente económicos (Nussbaum, 2007). Por tanto, la compasión debe mover a los ciudadanos a exigir a los gobiernos, instituciones y entidades con capacidad de decisión que actúen en favor de aquellas personas que como náufragos se ahogan en sus necesidades apremiantes. La ciudadanía compasiva también nos debe llevar a enfocarnos en el trance de personas que son socialmente desiguales $\mathrm{y}$, por esto mismo, en cierta medida impotentes para reaccionar ante situaciones de discriminación, hostilidad y otras formas de comportamiento que dan cuenta de los alcances de la crueldad humana. Al respecto, Jimenez (2016) nos dice: "Ciudadanos con una compasión debidamente refinada pueden promover la creación de instituciones justas que nos excusarían de apoyarnos necesaria y completamente en todo momento en la misma compasión" (p. 157).

Así, pues, ante la pregunta ¿cómo asegurar a todos los ciudadanos de una nación, y de la humanidad en general, las condiciones adecuadas para poder vivir una vida digna y floreciente en la cual cada uno pueda desarrollar sus proyectos, ilusiones y metas existenciales? La respuesta desde una ciudadanía compasiva aboga por exigir al Estado generalizar esas condiciones de vida digna mediante la implementación de instituciones públicas, democráticas, transparentes y legítimas que concreticen el espíritu que anima este enfoque de las capacidades. Se trata de formar una racionalidad pública que se nutre del refinamiento de ciertas emociones políticas, como la compasión, que posibilitan una democracia renovada en donde se ataque el frecuente problema de la incapacidad para ver al prójimo como alguien plenamente humano. Esto implica por tanto incluir una perspectiva compasiva en el derecho, las leyes y las instituciones públicas, más allá de lo que se espera que todo gobierno mínimamente haga por suplir las necesidades básicas de todos los ciudadanos (Nussbaum, 2014).

\section{Conclusiones}

La recuperación de las emociones morales y su vínculo con ciertas nociones de justicia social ocupa hoy en día un lugar privilegiado en la reflexión filosófica. Después de un largo periodo de tiempo en que estos aspectos fueron poco tratados en la reflexión moral contemporánea, hoy en día asistimos a importantes debates sobre el papel de las emociones en la vida moral y en la deliberación política. No obstante, en la historia 
de la filosofía encontramos valiosas aproximaciones a este problema como las ideas desarrolladas por los sentimentalistas británicos en torno a la benevolencia y los sentimientos morales que dan cuenta de nuestra naturaleza humana bondadosa y noble, así como también de nuestra tendencia básicamente relacional que nos aleja de la visión pesimista del hombre como ser solitario y egoísta que sólo tiende puentes para vivir con otros por el puro temor de perecer.

En contraste con la idea del hombre malo y egoísta surgida en la modernidad, los sentimentalistas escoceses del siglo XVIII proponen al hombre benevolente y compasivo cuya voluntad y deseo de hacer el bien a otros le permite disfrutar de la compañía y reciprocidad de sus congéneres, lo cual constituye la base para una vida social estable y armoniosa. Para estos pensadores la benevolencia es una inclinación natural que tiene que ver con la vida pública y se expresa mediante los sentimientos morales de aprobación de aquellas conductas y caracteres que se consideran correctos y virtuosos, y con la condena de aquellos comportamientos que traslucen vicio y daño para la sociedad.

Estos principios filosóficos que defienden un papel decisivo de los sentimientos en la vida moral anteceden a muchas de las discusiones actuales sobre la relación entre moral y emociones, y constituyen las bases para comprender la conexión que hoy en día tiene una filosofía de las emociones con las reflexiones sobre justicia social, derechos humanos y calidad de vida.

Así como los sentimentalistas modernos realizaron importantes esfuerzos por establecer relaciones entre los sentimientos y la vida moral, actualmente encontramos autoras como Martha Nussbaum que defienden un fuerte vínculo entre emociones, moralidad y justicia política. No es que exista un continuum teórico entre los sentimentalistas y la obra de la filósofa norteamericana, pero ciertamente nos encontramos ante dos reflexiones filosóficas que pueden establecer un dialogo al compartir conceptos morales claves como la benevolencia y la compasión que configuran nuestra textura emocional.

El estudio de las emociones ocupa un lugar central dentro del pensamiento filosófico de Nussbaum, pero su interés por comprender la naturaleza de las emociones se encuentra fuertemente ligado a su preocupación por generar diversos principios éticos normativos que orienten a las actuales sociedades democráticas y liberales a defender un modelo de humanidad y de ciudadanía en donde la consideración de la vulnerabilidad que nos es constitutiva se convierta en el vínculo que enlaza las motivaciones de los ciudadanos con la base política del Estado de derecho que debe velar por los menos favorecidos.

De acuerdo con lo anterior, podemos afirmar que Nussbaum es una autora que recorre diversas tradiciones de pensamiento que le permiten rehabilitar una perspectiva que sin duda se había descuidado en el último siglo: la centralidad de las emociones en la vida moral y las consecuencias prácticas que se derivan de esta reflexión tanto para la vida individual como para la deliberación pública. En este sentido, aspectos que son de gran relevancia para la vida en sociedad, como son la benevolencia, la preocupación por los otros, la educación de los ciudadanos, el derecho, el arte y la cultura política, son, entre otros elementos, realidades humanas que terminan siendo afectadas por el repertorio emocional que nos conforma, de ahí el potencial moral que Nussbaum percibe en el cultivo y refinamiento de ciertas emociones, como la compasión, que considera fundamental para edificar relaciones constructivas con los otros y para instaurar una sociedad justa y decente.

Nussbaum entiende desde esta perspectiva que el liberalismo necesita ciudadanos con una motivación democrática de tipo emocional que los lance a la acción pública, asunto que no se da por vía legal o de decretos, sino mediante el adecuado cultivo de virtudes cívicas. Esto se explica asumiendo la metáfora de las emociones como combustible que aviva nuestro deseo de ser justos, de reconocer al otro como persona y de incluir en nuestras preocupaciones cotidianas las necesidades de los sectores sociales menos favorecidos para alcanzar una verdadera estabilidad política. En este sentido, emociones con alta eficacia motivacional como la compasión garantizan que los ciudadanos se preocupen por la dignidad y bienestar de los demás, particularmente de aquellos que por diversas condiciones de injusticia social se encuentran en peligro de florecimiento humano. Su visión de la compasión se extiende hasta la deliberación pública y a la pregunta por las demandas que hoy en día se le deben hacer a un Estado para que sea justo, esto es lo que la autora denomina el surgimiento de una ciudadanía compasiva que propende por la igual dignidad humana para todos. 
Emociones, comprensiones sobre ciudadanía, justicia social y lucha por la dignidad humana constituyen un núcleo de reflexión indisoluble en el pensamiento de Nussbaum; y no sólo se trata de un asunto teórico, sino de discusiones normativas que se espera se concreticen en políticas públicas que promuevan las capacidades a las cuales toda persona debe tener acceso para alcanzar una vida floreciente y digna de ser vivida. Es una propuesta que contrasta abiertamente con el sobrecogedor escenario de desvalorización de la vida, asco, degradación del otro, violencia y discriminación al cual asistimos en lo que va corriendo del siglo XXI.
La ciudadanía compasiva es, pues, una original reflexión que nos recuerda nuestra naturaleza benevolente capaz de hacerse cargo de nuestra vulnerabilidad esencial y del sinnúmero de padecimientos a los cuales estamos expuestos en este mundo. Todo esto conduce a comprender que una de las tareas de la filosofía es ayudar a los seres humanos a hacerse personas que cuidan de otros: esta reflexión que se ha denominado "de la benevolencia a la compasión" es un aporte para que no se detenga esta discusión. 


\section{Referencias}

Arteta, A. (1996). La compasión, apología de una virtud bajo sospecha. Barcelona : Paidós.

Dixon, T. (2008). The Invention of Altruism. Making Moral Meanings in Victorian Britain. New York: Oxford University Press.

Feather, N. (2006). Deservingness and emotions: Applying the structural model of deservingness to the analysis of affective reactions to outcomes. European Review of Social Psychology, $17,38-73$.

Fiering, N. (1981). Moral Philosophy at the Seventeenth Century. Harvard: Chapell Hill.

Gil, M. (2016). La noción de evaluación eudaimonista en la teoría cognitiva de las emociones de Martha Nussbaum. Trans/ Form/Acao-Revista de Filosofia, 39(3), 191-210.

Gonzalez, E. (2007). Una lectura actualizada de la ética aristotélica. La mirada de Martha Nussbaum. Quaderns de filosofia i ciencia, (37), 91-100.

Gu, J., Cavanagh, K., Baer, R., \& Strauss, C. (2017). An empirical examination of the factor structure of compassion. PlosOne, 12(2), 1-17.

Hurtado, J. (2013). Adam Smith y la escuela del sentido moral. Ideas y valores, LXII(153), 45-72.

Hutcheson, F. (1999). Escritos sobre la idea de virtud y sentido moral. Madrid: Centro de Estudios Constitucionales.

Hutcheson, F. (2004). An Inquiry into the Original of our Ideas of Beauty and Virtue (1725 ed.). Indianapolis: Liberty Fund.

Izard, C. (1977). Human Emotions. New York: Plenum Press.

Jiménez, D. (2016). Educación emocional para una ciudadanía democrática. Quito: Centro de Publicacioines Pontificia Universidad Católica del Ecuador.

Lariguet, G. (2015). Tres interpelaciones criticas a Political Emotions. Why Love Matters for Justice de Martha Nussbaum. En A. Fleck, E. Reich, \& J. M. Muniz (Eds.), Crise da democracia?: Crisis de la democracia? (pp. 79-112). Florianópolis: Nefiponline.

Lewis, M. (1993). The emergence of human emotions. En M. Lewis, \& J. Haviland-Jones, Handbook of emotions (pp. 265280). New York: The Guilford Press.

Mandeville, B. (2001). La fábula de las abejas: o los vicios privados hacen la prosperidad pública. México: Fondo de Cultura Económica.

Mauri, M. (2005). El conocimiento moral. Shaftesbury, Hutcheson, Hume, Smith, Brentano, Scheler, Santo Tomás. Madrid: Rialp.

Mélich, J. C. (2010). Ética de la compasión. Barcelona: Herder.

Neblett, W. (1981). The Role of Feelings in Morals. Washington: University Press of America.
Nussbaum, M. (1996). Compassion: the basic social emotion. Social Philosophy and Policy, 13(1), 27-58.

Nussbaum, M. (1997). Justicia poética. La imaginación literaria y la vida pública. Barcelona: Andrés Bello.

Nussbaum, M. (2002). Las mujeres y el desarrollo humano. El enfoque de las capacidades. Barcelona: Herder.

Nussbaum, M. (2003). Compassion and Terror. Daedalus, 132 (1), 10-26.

Nussbaum, M. (2006). El ocultamiento de lo humano. Repugnancia, verguenza y ley. Buenos Aires: Katz.

Nussbaum, M. (2008). Paisajes del pensamiento. La inteligencia de las emociones. Barcelona: Paidós.

Nussbaum, M. (2012). Crear capacidades: propuesta para el desarrollo humano. Barcelona: Paidós.

Nussbaum, M. (2014). Emociones políticas. ¿Por qué el amor es importante para la justicia? Barcelona: Paidós.

Oviedo, L. (2016). Altruismo y misericordia. Scripta Theologica, 48, 173-198.

Pinedo, I., \& Yáñez, J. (2017). Las emociones y la vida moral: una lectura desde la teoría cognitivo-evaluadora de Martha Nussbaum. Veritas, 36, 47-72.

Salguero, M. (2011). La benevolencia: genealogía de una virtud política ilustrada. Granada: Editorial Universidad de Granada.

Seglow, J. (2005). The Ethics of altruism. London: Frank Cass Pubishers.

Seoane, J. (2001). De la benevolencia a la simpatía. Pensamiento, 57(217), 95-124.

Seoane, J. (2004). Del sentido moral a la moral sentimental: el origen sentimental de la identidad y ciudadanía democrática. Madrid: Siglo Veintiuno.

Shaftesbury. (1997). Investigación sobre la virtud y el mérito. Madrid: Consejo Superior de Investigaciones Científicas.

Sobrino, J. (1992). El principio misericordia. Santander: Sal Terrae.

Sobrino, J. (1993). Jesucristo liberador. Lectura histórico teológica de Jesús de Nazaret. Madrid: Trotta.

Vives, J. L. (1953). Del socorro de los pobres o de las necesidades humanas. Madrid: Atlas.

Weiner, B. (1985). An attributional theory of achievement-related motivation and emotion. Psychological Review, 29, 548-573.

Wendel, F. (1965). Calvin the origins and development of his religious thought. London: Collins.

Zarka, Y. (1997). Hobbes y el pensamiento político moderno. Barcelona: Herder. 


\section{Notas}

1 Hobbes en su proyecto de fundamentar el saber político establece que entre los hombres hay una rivalidad permanente por el honor y la dignidad, situación que crea la envidia, el odio y la guerra. También establece que, al contrario del animal, para el que el bien privado no difiere del bien común, el hombre se compara con los otros, y sólo puede saborear verdaderamente lo que está por encima de la suerte común, de aquí que busca la superioridad y el dominio sobre los demás. Así, pues, su búsqueda frenética de intereses particulares lo lleva a la rivalidad, la desconfianza y el deseo de gloria, comportamiento que se traduce en guerra con los demás y en una grata conciencia del bienestar propio (Zarka, 1997). Mandeville dirá con suspicacia que los vicios privados hacen la prosperidad pública, de manera que toda acción aparentemente benevolente no es más que una complacencia en el amor propio, no son más que actos de orgullo que el hombre consuma en su interior puesto que siempre permanece la naturaleza egoísta de sus móviles (Mandeville, 2001).

2 Para el pensamiento calvinista moderno el hombre es totalmente incapaz de salvarse a sí mismo a cuenta de la caída total de Adán en el Jardín del Edén. Esto significa que la personalidad íntegra del hombre quedó afectada por el pecado: su voluntad, entendimiento y afecto han sido tocados por la depravación o corrupción del género humano, que constituye la condición natural de nuestra existencia, pues como dice la Biblia "por un hombre entró el pecado en el mundo". Esta visión antropológica negativa que se desprende de la teología calvinista reforzó diversas nociones del hombre como un ser de naturaleza egoísta que solo busca su propio beneficio, que no piensa en los demás y constantemente está inclinado hacia el mal (Wendel, 1965).

3 Volver al pensamiento aristotélico permite recuperar para el discurso y debate en el terreno de la ética y de la política cuestiones tales como: la pregunta por la felicidad (y no sólo por la justicia), la pregunta por las virtudes morales, cívicas y políticas (y no sólo por las normas), la pregunta por la educación de los sentimientos morales (y no sólo la transmisión de reglamentaciones y procedimientos), la pregunta por la forja del carácter individual y colectivo a la altura de la moral alcanzada por la sociedad (y no sólo en la definición de procedimientos justos) por mencionar algunos puntos centrales (Gonzalez, 2007, pág. 92).

4 En Las mujeres y el desarrollo humano (2002) y en Crear capacidades: propuesta para el desarrollo humano (2012), Nussbaum expone la lista de capacidades básicas que considera son el fundamento filosófico de una teoría parcial de la justicia: Vida, salud corporal, integridad corporal, sentidos, imaginación y pensamiento, emociones, razón práctica, afiliación, cuidado de las otras especies, juego y control del propio entorno. Nussbaum considera que esta lista de capacidades guarda una estrecha relación con el enfoque de los derechos humanos fundamentales. La autora considera que puede concitar un acuerdo amplio intercultural parecido a los acuerdos internacionales alcanzados a partir de los derechos humanos básicos, por consiguiente ve su enfoque de las capacidades como una especificación del enfoque de los derechos humanos asociados a la idea de dignidad humana (Jiménez, 2016). 